\title{
AVENIDAS FLUVIALES E INUNDACIONES EN EL MEDIO VINALOPÓ EN EL TRÁNSITO DE LOS SIGLOS XIX Y XX
}

\author{
Ana Pilar Pérez García-Torres \\ Instituto Universitario de Geografía \\ Universidad de Alicante
}

\section{RESUMEN}

El presente análisis evidencia la importancia que han tenido las avenidas fluviales e inundaciones en el Medio Vinalopó a finales del siglo XIX y principios del XX. El estudio de episodios históricos de avenidas resulta esencial para mejorar las actuaciones de prevención, seguridad y control, que persiguen la reducción de efectos dañinos en este ámbito alicantino.

Palabras clave: inundaciones en el Vinalopó Medio; causas atmosféricas; efectos.

\section{SUMARY}

The present analysis evidences the importance that have had the fluvial avenues and floods in the Medio Vinalopó at the end of the XIX century and principles of the XX one. The study of historical episodes of avenues is essential to improve the performances of prevention, security and control, that pursue the reduction of harmful effects in this alicantino environment.

\section{Características del area de estudio}

El Vinalopó corre desde Serra de Mariola, a unos $1.000 \mathrm{~m}$ de altitud, hasta su difusa desembocadura en l'Albufera d'Elx. Responde claramente a la categoría de río-rambla, dicha expresión no es, como pudiera pensarse, reciente. Como señala Gil Olcina: «los musulmanes llamaron al Vinalopó wad-arrambla. En verdad, la denominación no puede resultar más apropiada y expresiva, ya que refleja el carácter híbrido de dichas corrientes, más identificadas, no obstante, con las segundas; de los ríos poseen el fluir continuo, de las ramblas su funcionamiento espasmódico, alta irregularidad, desmesurados lechos ordinarios y fulminantes avenidas» (Gil Olcina, 1993), que multiplican exponencialmente sus módulos normales. Condición de ríos-ramblas asumen también en tierras alicantinas Ama- 
dorio y Monnegre. En realidad esta cuenca fluvial está formada por tres cubetas, no demasiado homogéneas, que se sitúan a lo largo de la fosa tectónica comprendida entre Villena y Elche: Alto Vinalopó, Vinalopó Medio y Bajo.

Las localidades de Elda y Petrer se emplazan en el tramo del Medio Vinalopó, espacio que puede presumir de estar totalmente avenado por el cauce principal, algo que no ocurre en las cubetas restantes. Y es que, en efecto, desde los relieves circundantes acude al Vinalopó una red importante de ramblas decisivas en la formación de avenidas. Ya que, pese a las reducidas dimensiones de sus cuencas vertientes (150 ó $200 \mathrm{~km}^{2}$ ), son capaces, en ocasiones excepcionales de generar máximos instantáneos superiores a $1.000 \mathrm{~m}^{3} / \mathrm{s}$. A ello se aúna, el importante desnivel que éstas deben salvar en pocos kilómetros.

La red hidrográfica que forman las ramblas que avenan el territorio ocupado por los municipios de Elda y Petrer se resuelve del modo siguiente:

a) Ramblas de Petrer o que interesan su término municipal: Rambla de Caprala, Santa Bárbara, Rambla de Puça — a la que se unen, entre otras, las de Badallet, Solana de Frare, de L'Almadrava, etc. - Cagallons, dels Gossos, Bateich, Colegiales, Barranquet, etc.

b) Ramblas de Elda o que penetran en su término: Rambla del Sapo, Rambla de la Melva, Barranco del Derramador, Rambla del Charco, Rambla del Bateig, etc.

Por otra parte, existen otras, no tan determinantes como las anteriores por no verter en esta cuenca, pero que resulta necesario mencionar por formar parte de la cuenca del Barranco de las Ovejas, responsable del episodio de avenida catastrófica de octubre de 1982 en Alicante, que provocó la devastación de todo el barrio de San Gabriel. Estas se localizan en la parte más oriental del término municipal de Petrer y son, concretamente, la Rambla de Choli y la Rambla de la Zarza, ambas se unen ya en término municipal de Agost.

La causa más frecuente de las avenidas tanto en este río-rambla, como en todos los de la cuenca occidental mediterránea, son las lluvias intensas causadas por la conjunción de toda una serie de factores atmosféricos favorables; entre ellos, la presencia de relieves próximos a la costa cuya disposición estructural favorece los fenómenos de disparo en la vertical de los flujos de aire que a ellos acuden cuando soplan vientos del primero y segundo cuadrantes. No obstante, resulta necesario señalar que la responsabilidad última de estas lluvias extraordinariamente copiosas y concentradas en el tiempo recae en el mar que, a través de una evaporación muy intensa en determinadas épocas y ocasiones, proporciona a la atmósfera los ingentes volúmenes de agua y el enorme caudal de energía requeridos en la génesis de estos hidrometeoros. Ello, conjugado con las irrupciones de aire frío en niveles altos de la troposfera, establece el calendario de lluvias catastróficas en los meses de septiembre a noviembre - denominados meses tardo-estivales, aquellos que, finalizada la estación astronómica estival, participan de los rasgos térmicos acumulados a lo largo del verano en la cuenca occidental del Mediterráneo-; y se producen bajo la forma de temporales de escasa duración, dos o tres días, en los que se recogen grandes cantidades de lluvia en el intervalo de pocas horas (Gil Olcina, 1989).

En este sentido resulta clarificador señalar alguna cifra estadística sobre el reparto y ritmo estacional de las precipitaciones, según datos de la red de observatorios del Medio Vinalopó. En primer lugar, el reparto estacional se establece como muestra el cuadro siguiente: 
Cuadro 1

PRECIPITACIONES MEDIAS ANUALES EN ELDA-PETRER ( $\mathrm{mm})$

\begin{tabular}{|c|c|c|c|c|c|c|c|c|c|c|c|c|}
\hline E & F & M & A & M & J & J & A & S & O & N & D & ANUAL \\
\hline 25.7 & 20.1 & 29 & 40.5 & 36.7 & 32.1 & 5.2 & 17.3 & 32 & 47.5 & 27.2 & 27.7 & 341 \\
\hline
\end{tabular}

FUENTE: Instituto Nacional de Meteorología.

Elaboración propia.

Dicha distribución muestra un régimen claramente mediterráneo, con la existencia de dos máximos: uno principal de otoño, que oscila entre los meses de septiembre y octubre, y otro máximo secundario en primavera, que suele presentarse en abril o mayo. En el primer máximo, las precipitaciones pasan a depender totalmente del gran reservorio de energía y vapor de agua en que se convierte el mar Mediterráneo. Factor indispensable en los aguaceros de fuerte intensidad horaria, ya que las altas temperaturas de las capas superficiales del agua del mar, durante los meses de verano, favorecen una evaporación intensa, provocando el aumento de la cantidad de vapor de agua en el aire. Por tanto, ello hace que se produzcan los máximos pluviométricos del año con precipitaciones de fuerte intensidad horaria. El invierno es bastante irregular en cuanto a precipitaciones, mientras que lo que caracteriza al verano es la sequía, centrada en los meses de julio y agosto.

El reparto estacional de las precipitaciones mencionado puede apreciarse en el cuadro siguiente:

Cuadro 2

REPARTO ESTACIONAL DE LAS PRECIPITACIONES EN ELDA-PETRER (mm)

\begin{tabular}{|c|c|c|c|}
\hline OTOÑO & INVIERNO & PRIMAVERA & VERANO \\
\hline 109.3 & 74.9 & 98.2 & 54.5 \\
\hline
\end{tabular}

FUENTE: Instituto Nacional de Meteorología.

Elaboración propia.

\section{Avenidas fluviales e inundaciones a finales del siglo XIX y principios del XX}

Son cinco las avenidas más importantes del Vinalopó desde finales de siglo XIX hasta principios de esta centuria. Provocaron fuertes llenas en toda la red de ramblas y barrancos de los términos municipales de Elda y Petrer que vierten al Vinalopó. Se trata de las riadas de 1884, 1898, 1902, 1906 y 1913.

El primero de estos episodios destaca, sin duda, por una fuerte inestabilidad atmosférica. En marzo de dicho año habían tenido lugar importantes inundaciones, de aciagas consecuencias en la Vega Baja del Segura y Ribera del Júcar. No obstante, se puede decir que el episodio más notable aconteció en septiembre, adquiriendo tal magnitud que está considerado como el más importante en la historia de la comarca por sus catastróficas consecuencias. En efecto, sobre las 22 y 23 horas del día 18 de septiembre de 1884, una gran tromba de agua se precipitó sobre las localidades de Elda, Petrer y Villena. Como consecuencia, se desencadenó una gigantesca riada que arrastró todo cuanto encontró a su paso. 
Navarro Pastor describe así la extremosidad del evento: «las montañas escupieron el agua hacia las ramblas y éstas se convirtieron en tumultuosos arroyos que todos a la vez fueron a volcarse sobre el ya crecido Vinalopó» (Navarro Pastor, 1981).

Las ramblas pertenecientes al término municipal de Petrer, por proceder de unos abruptos relieves, salvando así desniveles bastante acentuados (Sierra del Cid y estribaciones del Macizo del Maigmó), fueron las primeras en recibir las aguas embravecidas. Como consecuencia se produjo la destrucción de dos molinos harineros, fábricas, varias fincas importantes, caminos y, además, el arranque de una gran cantidad de árboles y arbustos. Desgraciadamente, en esos cauces se hallaban molinos harineros y corrales dedicados a ganadería menor (Payá Poveda, 1991), lo que motivó el arrastre de animales, así como de sacos de harina y grano. Aun así, no hubo que lamentar pérdidas humanas como en Elda. En esta localidad se cebó la tragedia: un molino de esparto fue inundado y murieron ahogadas tres mujeres que habitaban en él. Igual ocurrió en el paraje de la Alfaguara, con una casa en la que vivía un anciano matrimonio. Muy cerca de este lugar fue destrozado por completo un molino de papel de estraza junto con los árboles y sembrados que había en el cauce del río. Pero la desgracia pudo adquirir tintes de catástrofe cuando la furiosa avenida llegó al puente de la Estación. Había sido construido cinco años antes, de fuerte sillería y de dos ojos. Alrededor de doscientas personas se hallaban contemplando en él la llegada de las aguas. El cronista Navarro Pastor narra así el suceso: «Al chocar la corriente contra la fuerte estructura del puente, se fue acumulando en él, sin poder pasar, los árboles, arbustos, animales muertos y demás objetos y materiales que arrastraban las aguas, embalsándose contra él y empujando de tal manera que con un estruendo horrísono todo el puente se fue abajo, quedando de él solamente parte de uno de los estribos. Afortunadamente, advertidos de la inminencia de la catástrofe por el primer crujido, todos los que se agolpaban en el puente corrieron hacia las salidas, no produciéndose víctima alguna» (Navarro Pastor, 1981). Aguas abajo, una vez roto el puente, la avenida arrasó el matadero, de reciente construcción, así como, en las inmediaciones de Novelda, árboles, cosechas, sembrados, frutos y una gran cantidad de tierra útil que, según este historiador, ascendía a dos mil tahullas. Asimismo, la ciudad quedó desabastecida de agua potable y de riego; sus conducciones fueron destrozadas.

Las consecuencias de esta gran avenida fueron catastróficas para una economía que ya estaba inmersa en una grave crisis agrícola y comercial, debido al terrible azote del cólera que infectaba a la provincia. Los frutos de la tierra no podían venderse, y tampoco las industrias funcionar, al estar totalmente prohibida por las autoridades la salida de mercancías y de productos.

El siguiente episodio tiene lugar en marzo de 1899, concretamente entre los días $10 \mathrm{y}$ 12. La causa atmosférica (vid. mapa) de este episodio de lluvias copiosas fue la génesis de una profunda depresión (744 mm de mercurio, en su ápice el día 10 de marzo) en el Golfo de Cádiz, que cruzó el Estrecho de Gibraltar y se situó, finalmente, en el denominado mar de Argel (Olcina Cantos, 1993). Esto hizo que se generara un intenso temporal con vientos fuertes de levante y lluvias copiosas en la mitad oriental peninsular. En estas jornadas se produjeron numerosos desbordamientos del Vinalopó, que afectaron, de manera especial, a los municipios de Villena, Sax, Elda, Petrer y Novelda.

La prensa alicantina se hizo amplio eco de este temporal. Así, un diario de la época, $E l$ Graduador, afirmaba: «El río Vinalopó ha sido el protagonista de estas últimas borrascas y lluvias... la palma se la ha llevado Villena, Sax y Elda...». En esta última localidad, el agua destruyó el puente provisional, construido tras la trágica riada de 1884. El correspon- 


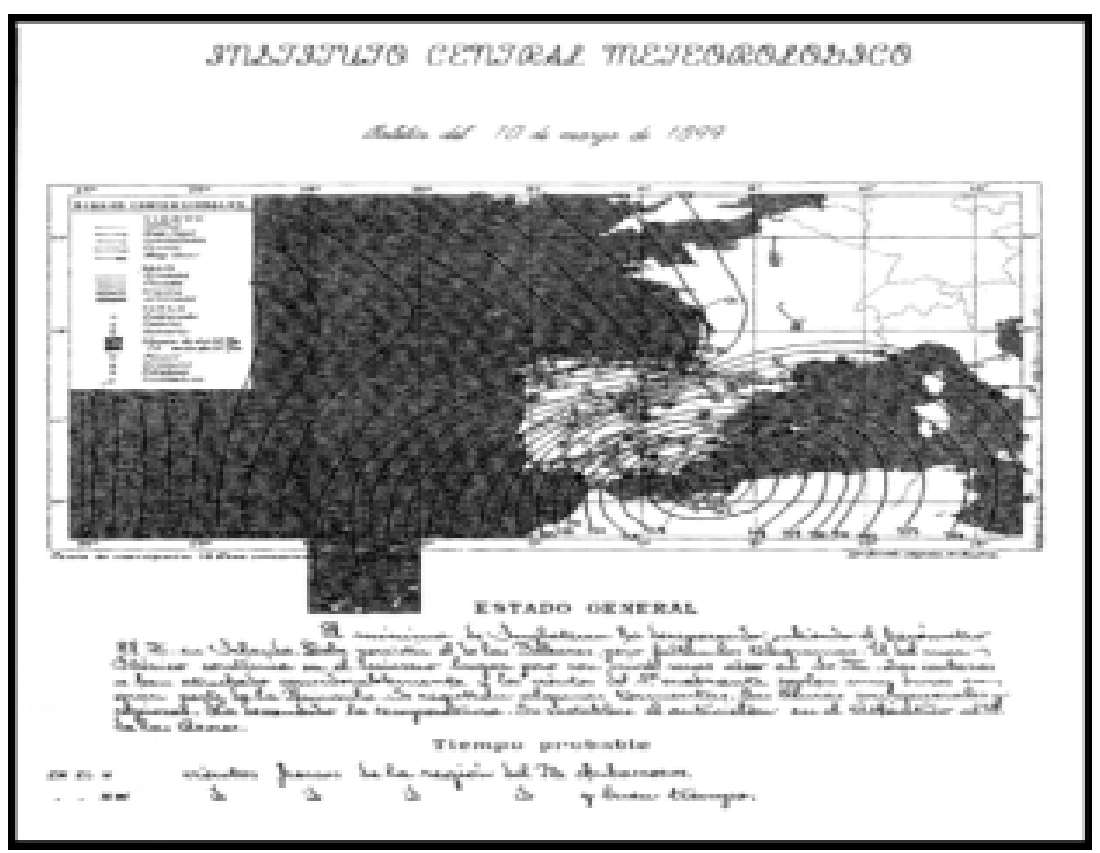

sal de El Noticiero relataba: «De los puentes que conducen á la estación no queda ni rastro... un total de 22 y más de mil tahullas de terreno de las orillas del río». El matadero municipal, situado a orillas del Vinalopó, fue de nuevo destrozado. Asimismo, en este diario, se daban a conocer las pérdidas económicas que, en esta localidad, ascendían a más de un millón de reales.

En Petrer todos los molinos que existían en la época, un total de nueve — según una planimetría de 1989—, sufrieron perjuicios de consideración, y según se afirmaba en El Noticiero, «fueron de tal importancia que será difícil que vuelvan a moler en muchos meses». Ante esta situación, otro periódico, La Correspondencia Alicantina, auguraba la continuidad del estado del tiempo para el día 13 así: «El cielo se halla cubierto de densas nubes, presagiando nuevos y más temibles daños. Dios haga que nos equivoquemos». El día 14 de marzo El Noticiero plasmaba la siguiente nota tranquilizadora del alcalde de Petrer: «el río Vinalopó lleva muy poca crecida sobre el nivel ordinario, descendiendo rápidamente... continúan repartiéndose socorros». En fin, las consecuencias fueron muy graves. Asimismo, en este diario, se atribuía la causa de la gran avenida a la destrucción de la rafa que dividía las aguas en los límites de la provincia.

En noviembre del año 1902 se registra otro episodio de lluvias intensas que afecta a todas las localidades de la comarca. Se produce entre los días 13 y 14. De nuevo, una situación de temporal de levante (vid. mapa), vuelve a causar unas jornadas intensamente lluviosas. Las condiciones de gran inestabilidad atmosférica existente sobre el Mediterráneo

1 En una planimetría de Petrer, correspondiente al año 1898 y puesta al día en 1987, aparecen un total de nueve molinos. 


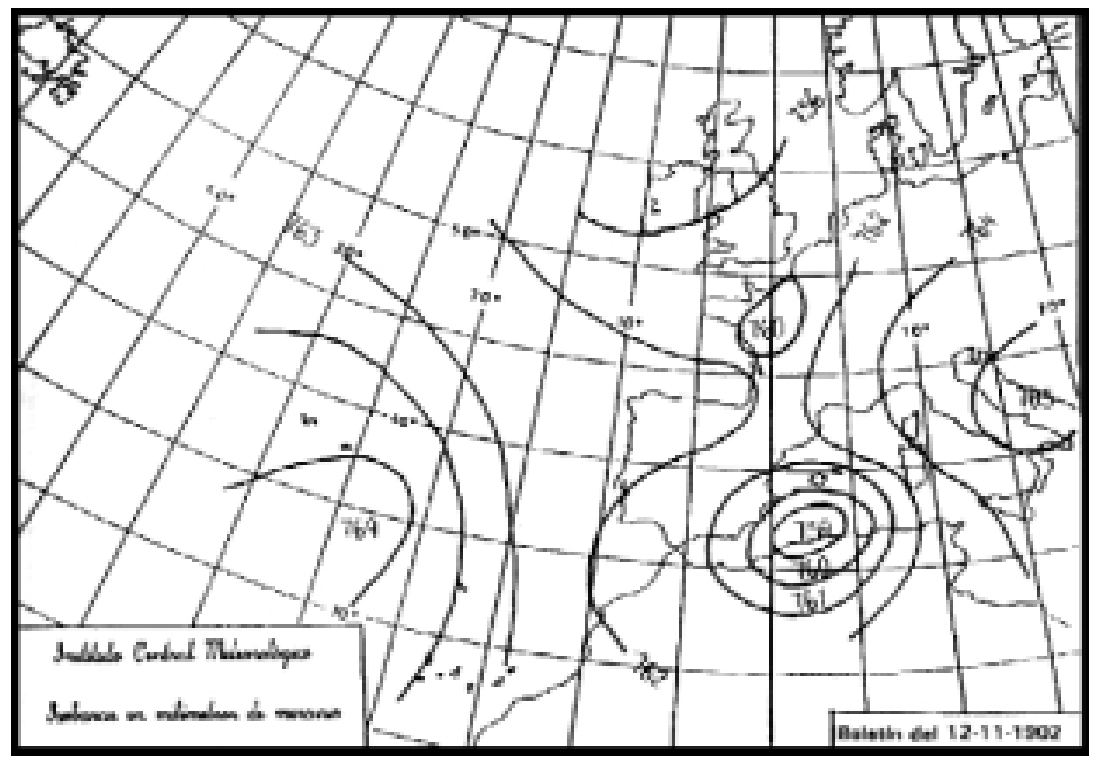

Occidental favorecen un desarrollo ciclogenético argelino imponiendo un régimen de bajas presiones en toda la cuenca occidental del Mediterráneo (Olcina Cantos, 1993).

Los efectos de esta tromba de agua se manifestaron de forma más grave en Elda, ya que las aguas arrastraron los dos puentes con que contaba la población: el que comunicaba con la estación de ferrocarril y el que había camino de Monóvar. Y es que durante la crecida no sólo circula agua por el cauce, sino que también existe un importante caudal sólido con elevada densidad de mezcla, algo que amplía poderosamente sus límites de carga. Por tanto, ríos y ramblas, en sus llenas, transportan tonelajes inverosímiles de limos, gravas e incluso bloques de grandes dimensiones, sin olvidar el arrastre de árboles, arbustos, animales y todo tipo de objetos. Cabe destacar que, desde épocas ancestrales, el hombre ha utilizado los cauces de ríos, ramblas y barrancos como auténticos vertederos; ello hace que, cuando se produzca un evento atmosférico de estas características, todos los desechos sean arrastrados por la corriente, provocando así la obstrucción de los ojos de puentes y un efecto de presa sobre las aguas, cuyo estadio final es su destrucción y la generación de una inesperada onda de avenida aguas abajo.

El diario El Noticiero recogía así esta avenida del Vinalopó: «La crecida fue tan grande como ninguna otra... los destrozos en los márgenes han sido muchos... el puente que une á Elda con la estación férrea, fue destruido y arrastrado por las aguas... Elda se encuentra incomunicada con la estación y con Monóvar $\gg^{2}$. Aunque la prensa no plasmara en esta ocasión lo ocurrido en Petrer, se puede deducir fácilmente tras haber analizado episodios anteriores. No olvidemos que las ramblas de su término son decisivas para formación de crecidas del Vinalopó - Rambla de Caprala, Santa Bárbara, Rambla de Puça, etc.—; aunque es poco probable que esta localidad, de elevado emplazamiento, sufra las consecuen-

2 Vid. diario El Noticiero de 15 de noviembre de 1902. 
cias de una inundación. Sin embargo, no se descarta la existencia de fuertes arrastres, deslizamientos de laderas e inundaciones en las inmediaciones de los barrancos y ramblas que rodean la población, al estar éstas ocupadas por el hombre desde muy antiguo.

De nuevo, en 1906, acontece un mes de septiembre extraordinariamente lluvioso. El parte meteorológico del día 26 anunciaba la existencia de una borrasca (vid. mapa) situada en el mar de Argel que vehiculaba vientos fuertes de levante hacia el sudeste peninsular, causando precipitaciones muy copiosas. En efecto, este día se desencadenó una fuerte tormenta que arrasó parte de las huertas de los términos de Elda y Petrer, merced a fuertes llenas de las ramblas del Almafrá, Cid y Puça. Se produjeron numerosos daños en los campos, molinos y caminos, e incluso dos niños fueron arrastrados por las aguas. Tras este episodio se creó una Comisión (Navarro Pastor, 1981), a cargo de concejales y propietarios perjudicados de los pueblos de Elda y Petrer, para el estudio de los daños producidos y los medios para evitar estas inundaciones; además del intento de recabar del Gobierno las medidas de defensa necesarias.

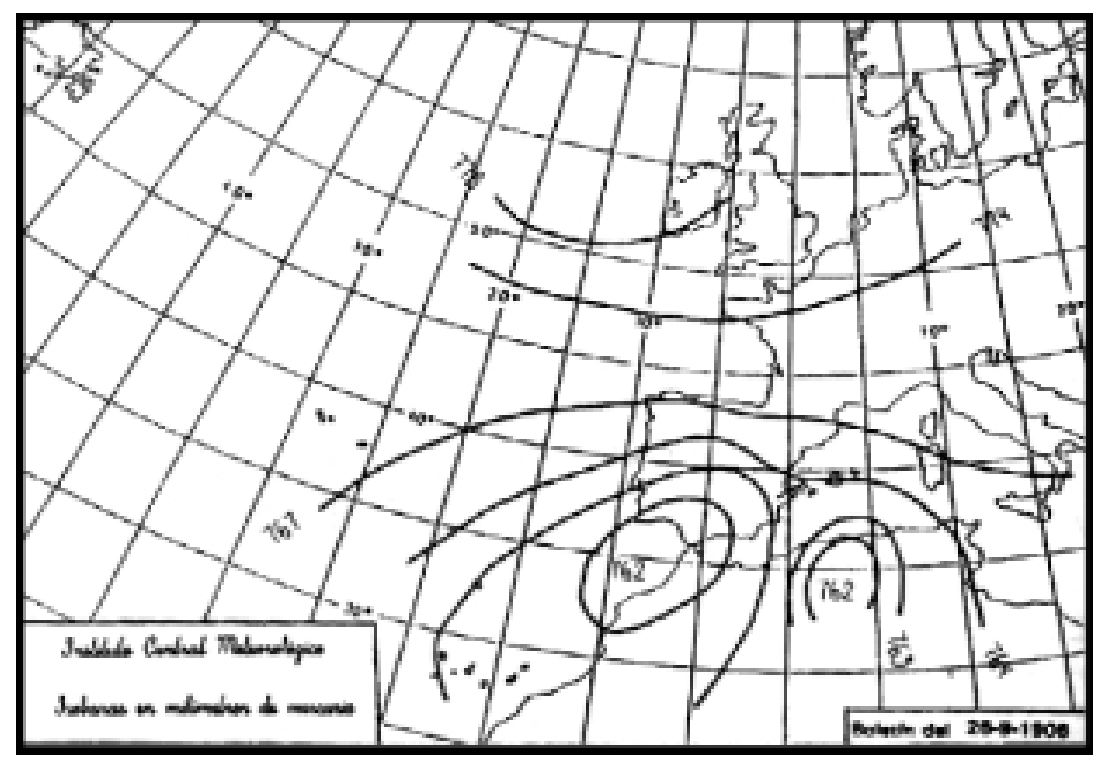

El verano de 1911 se conoció el proyecto de construcción de un canal en Villena para la desviación del curso del Vinalopó (Navarro Pastor, 1981). El propósito era sanear una gran superficie de terrenos incultos donde se desparramaban las aguas de avenida de Biar, Benejama y Bañeres. Ello suponía que todos esos caudales, que eran retenidos en los terrenos salobreños de Villena, incrementarían aún más el cauce del río, que ya en la riada de 1884 causó incalculables daños en las propiedades ribereñas. Evidentemente, ahora se veían amenazados los edificios industriales cercanos a éste. Para intentar paliar este peligro, el ayuntamiento de Elda acordó, el 19 de noviembre de 1911, solicitar al Ministerio de Fomento que fuera canalizado el río Vinalopó en su trayecto por el término municipal de esta localidad. No se consiguió tal propósito. 
Dos años más tarde, concretamente el día 8 de septiembre de 1913, la descarga de una impresionante tromba de agua motivó el arrastre del puente del camino de Elda a Monóvar, así como el de la Estación. La situación atmosférica que generó el desencadenamiento de estos intensos chubascos fue la instalación de dos campos depresionarios (vid. mapa): uno sobre el espacio sinóptico peninsular y el otro sobre el mediterráneo occidental (Olcina Cantos, 1993).

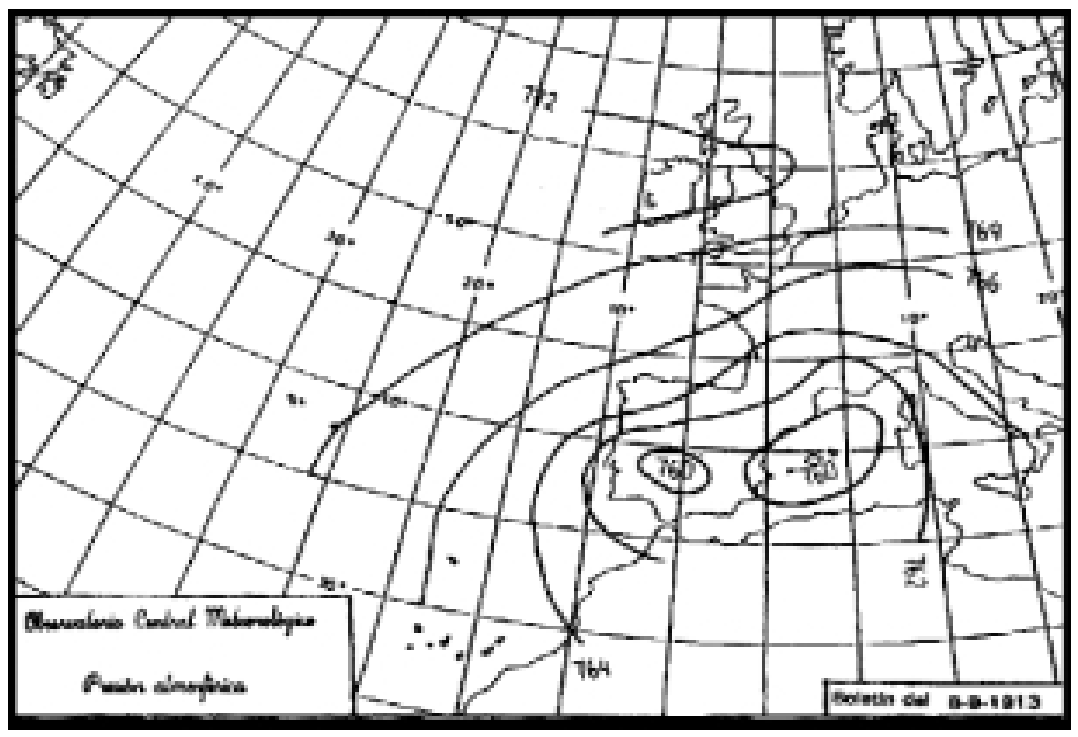

El día 10 de septiembre, en portada del Diario de Alicante, se podía leer: «La tormenta en Elda»; y en líneas posteriores, el corresponsal describía el cuadro siguiente: «Por la partida de la Torre cruza una rambla: momentos después de comenzar la tormenta saltó impetuosamente el caudal que bajaba por dicha rambla e invadiendo las viñas, los huertos, la carretera y la vía férrea arrastraba cuanto a su paso se oponía». Los vecinos de las casas de labor de Elda huían bajo las inclemencias del aguacero. Según cuenta dicho diario «muchos de ellos no se atrevían a salvar sus enseres de sus viviendas. Otros se refugiaban en las alturas...». Los daños ocasionados en los viñedos y en las demás plantaciones eran incalculables. Reinaba una gran consternación entre los labradores y campesinos de este pueblo. Ante esta situación se pidieron socorros al gobierno y, días más tarde, este mismo diario anunciaba que el ministro de Fomento pediría un crédito extraordinario para remediar, en parte, los daños causados en la provincia de Alicante. En definitiva, se trataba de una política de parcheo, puesto que costaba menos llevar a cabo políticas curativas que preventivas. No obstante, conviene indicar en este punto que a partir del siglo XIX comienza la adopción de medidas estructurales ante estos eventos, adquiriendo máximo desarrollo en la primera mitad del actual. No obstante, tendrán que pasar todavía más 70 años para que comiencen a realizarse en tierras alicantinas verdaderas políticas de defensa contra avenidas. Entre éstas destaca el desarrollo de los Planes de Defensa contra Avenidas de las cuencas del Segura y Júcar, la implantación del Sistema Automático de Información 
Hidrológica (S.A.I.H) y la realización de obras de defensa en el cauce del Vinalopó llevadas a cabo en diversas ciudades del valle (Elda, Sax, Novelda).

\section{Conclusión}

Las condiciones agrícolas de los suelos y la presencia de agua han sido factores determinantes en la atracción del poblamiento desde épocas ancestrales en todo el espacio comprendido por la cuenca del Vinalopó, pese a toda una gama de dificultades, entre ellas, las que devienen de sucesos climáticos como sequías e inundaciones.

En este sentido valdría la pena subrayar, a pesar de sus consecuencias, la importancia que tuvo, tanto en estos términos municipales como en tantas otras sociedades rurales de ambientes subáridos, el riego con aguas de avenida, ya que la carencia de agua para riego limitaba las cosechas y el desabastecimiento de una incipiente industria de materias primas. Prueba de ello es el sistema de derivación de aguas de avenida, denominado en estas tierras, de derramador ${ }^{3}$. Estas obras pueden observarse fundamentalmente en las torrenteras de la orografía petrelense, siendo las más importantes las unidas a la rambla de Puça. Valdría la pena recordar lo que, en las postrimerías del siglo XVIII y refiriéndose a estas tierras, advertía el ilustre botánico Cavanilles: «Los truenos que en otras partes sirven de señal para retirarse a sus habitaciones, lo son aquí para salir en busca de las aguas y deseado riego».

De todo ello subyace la existencia de una conciencia de los efectos, bien positivos, bien negativos, de las avenidas fluviales. No obstante, desde mediados del siglo XX, se ha producido un progresivo abandono de esta práctica junto a otras, no menos importantes, como son: los aterrazamientos, cultivos con ciclo vegetal adaptado a las condiciones atmosféricas, edificaciones ajenas a llanos de inundación, etc. Algo que ha modificado las condiciones de escorrentía y el régimen hidrológico de las cuencas vertientes de estos ámbitos, incrementándose con ello el grado de riesgo natural de avenidas.

\section{Bibliografía}

AMAT Y SEMPERE, L. (1983): Elda, su antigüedad y su historia. Elda. (Facsímil del manuscrito. Valencia. Ayto. de Elda y Univ. de Alicante, 2t.).

BALBOA ZARAGOZA, E. (1996): «Ocupación de ramblas y barrancos en la Comarca del Bajo Segura: Análisis-Diagnóstico de la situación en alguno de sus municipios». Investigaciones Geográficas, ${ }^{\circ}$ 17. Alicante, pp. 149-162.

BAUTISTA MARTÍN, J. (1989): «Las avenidas en la cuenca del Segura y los planes de defensa». Avenidas fluviales e inundaciones en la Cuenca del Mediterráneo. Instituto Universitario de Geografía. Caja de Ahorros del Mediterráneo. Alicante, pp. 469-482.

BRU RONDA, C.: Caminos del agua. El Vinalopó. Confederación Hidrográfica del Júcar. Valencia, 1992.

CALVO GARCÍA-TORNEL, F. (1989): «Grandes avenidas e inundaciones históricas». Avenidas fluviales e inundaciones en la Cuenca del Mediterráneo. Instituto Universitario de Geografía. Caja de Ahorros del Mediterráneo. Alicante, pp. 333-345.

3 Consistía en rudimentarias presas en el lecho de las ramblas desde las cuales derivaban agua hacia las heredades, al tiempo que, indirectamente, laminaban la onda de crecida. 
CAMARASA BELMONTE, A.M. (1995): Génesis de crecidas en pequeñas cuencas semiáridas: Barranc de Carraixet y Rambla del Poyo. Ministerio de Obras Públicas, Transporte y Medio Ambiente. Confederación Hidrográfica del Júcar. Valencia.

CANALES MARTÍNEZ, G. (1989): «Inundaciones en la Vega Baja del Segura». Avenidas fluviales e inundaciones en la Cuenca del Mediterráneo. Instituto Universitario de Geografía. Caja de Ahorros del Mediterráneo. Alicante, pp. 415-434.

CAPEL MOLINA, J.J. (1987): «Inundaciones y avenidas de los ríos del Sureste Español». Papeles de Geografía, no 13. Universidad de Murcia. Murcia, pp. 75-86.

CAVANILLES, A.J. (1972): Observaciones sobre la Historia Natural, Geografía, Agricultura, Población y Frutos del reyno de Valencia. Madrid. Imp. Real. 1795-97. 2 vols. (ed. facsímil). Albatros. Valencia.

GIL OLCINA, A. (1983): Lluvias Torrenciales e Inundaciones de Alicante. Instituto Universitario de Geografía. Universidad de Alicante. Alicante.

GIL OLCINA, A. (1986): Inundaciones en la Ciudad y Término de Alicante. Instituto Universitario de Geografía. Universidad de Alicante. Ayuntamiento de Alicante. Alicante.

GIL OLCINA, A. (1989): «Causas Climáticas de las Riadas». Avenidas fluviales e inundaciones en la Cuenca del Mediterráneo. Instituto Universitario de Geografía. Caja de Ahorros del Mediterráneo. Alicante, pp. 15-30.

GIL OLCINA, A. (1991): «Avenidas fluviales e Inundaciones». Atlas temático de la Comunidad Valenciana, $\mathrm{n}^{\circ}$ 8. Diario Información. Ed. Prensa Alicantina, S.A. Alicante.

GIL OLCINA, A.: La propiedad de aguas perennes en el sureste ibérico. Universidad de Alicante. Alicante, 1993.

GIL OLCINA, A. y OLCINA CANTOS, J. (1997): Climatología General. Ed. Ariel. Barcelona.

GÓMEZ MENDOZA, J. y ORTEGA CANTERO, N. (1989): «Inundaciones Históricas y la Génesis de la Acción Hidrológico-Forestal en España (1855-1983)». Avenidas fluviales e inundaciones en la cuenca del Mediterráneo. Instituto Universitario de Geografía. Caja de Ahorros del Mediterráneo. Alicante, pp. 285-298.

LÓPEZ GÓMEZ, A. (1976): «Los Riesgos de Avenida en la huerta de Alicante». Boletín de la Real Sociedad Geográfica, pp. 371-379.

LÓPEZ GÓMEZ, A. (1989): «Aguaceros Extraordinarios e Inundaciones en la Costa Mediterránea Española (1957-1982)». Avenidas fluviales e inundaciones en la Cuenca del Mediterráneo. Instituto Universitario de Geografía. Caja de Ahorros del Mediterráneo. Alicante, pp. 31-50.

MARTÍN VIDE, J. (1984): Pluges $i$ inundacions a la mediterrània. Ed. Ketres. Barcelona.

MARTÍN VIDE, J. (1990): Mapas del tiempo: Fundamentos, interpretación e imágenes de satélite. Ed. Oikos Tau. Barcelona.

MATEU BELLÉS, J. (1988): «Crecidas e inundaciones en el País Valenciano». Guía de la Naturaleza de la Comunidad Valenciana. Generalitat Valenciana. Valencia, pp. 595-654.

MATEU BELLÉS, J. (1989): «Ríos y ramblas mediterráneos». Avenidas fluviales e inundaciones en la Cuenca del Mediterráneo. Instituto Universitario de Geografía. Caja de Ahorros del Mediterráneo. Alicante, pp. 133-150.

MATEU BELLES, J. (1990): «Avenidas y riesgos de inundación en los sistemas fluviales mediterráneos de la Península Ibérica». Boletín de la A.G.E. n 10. Madrid, pp. 45-86.

MARCO AMORÓS, M. (1987): «Venida de agua de lluvia en 1571. Endorreísmo y avenamiento precario en el término de Villena (Alicante)». Investigaciones Geográficas. $\mathrm{n}^{\circ}$ 20. Alicante, pp. 163-180. 
MINISTERIO DE OBRAS PÚBLICAS Y DIRECCIÓN GENERAL DE PROTECCIÓN CIVIL. (1992): Las inundaciones en la España Peninsular. Madrid.

MORALES GIL, A. (1969): «El riego con aguas de avenida en las laderas subáridas». Papeles de Geografía, tomo I. Murcia, pp. 167-183.

MORALES GIL, A. (1983): «Las crecidas de los barrancos de las Ovejas y Agua Amarga. Octubre 1982». Estudios Geográficos. nº 170-171. Madrid, pp. 143-170.

NAVARRO PASTOR, A. (1981): Historia de Elda. Tomo I-II. Caja de Ahorros Provincial. Alicante.

OLCINA CANTOS, J. (1993): Episodios meteorológicos de consecuencias catastróficas en las tierras alicantinas (1900-1990). Tesis Doctoral. Instituto Universitario de Geografía. Alicante.

OLCINA CANTOS, J. (1994): Tormentas y granizadas en las tierras alicantinas. Instituto Universitario de Geografía. Alicante.

OLCINA CANTOS, J. (1994): Riesgos climáticos en la península ibérica. Ed. Acción Divulgativa. Madrid.

OLCINA CANTOS, J. (1995): «El factor climático y la ordenación del territorio: los riesgos climáticos». Situaciones de riesgos climáticos en España. Instituto Pirenáico de Ecología. Jaca. Huesca. pp. 15-69.

PAYÁ POVEDA, J. M. (1991): «Agricultura y propiedad de la tierra en Petrer en 1900». Bitrir, no 13-14. Exmo. Ayto. de Petrer. Petrer. pp. 205-235.

PÉREZ CUEVA, A.J. (1994): Atlas climàtic de la Comunitat Valenciana (1961-1990). Generalitat Valenciana. Valencia.

PÉREZ MEDINA, T. (1994-95): «La molinería hidráulica de la Ilustración en las comarcas del Vinalopó». Alebus, no 4 -5. Elda, pp. 180-204.

QUEREDA SALA, J. (1989): «Las interacciones atmósfera-océano en la climatología del Mediterráneo Occidental». Avenidas fluviales e inundaciones en la cuenca del Mediterráneo. Instituto Universitario de Geografía. Caja de Ahorros del Mediterráneo. Universidad de Alicante. Alicante, pp. 67-88. 